\title{
INTRODUCTION OF SMART PACKAGING SYSTEMS IN THE MARKET OF LATVIA - ATTITUDES OF MANUFACTURERS AND RETAILERS
}

\author{
Vjaceslavs Kocetkovs, Sandra Muizniece-Brasava \\ Latvia University of Life Sciences and Technologies, Latvia \\ kvsxc70@gmail.com
}

\begin{abstract}
Perfect packaging exists in nature - examples include banana peel (Musa sapientum fixa cortices L.) and eggshell (Ovi testa L.), together with the many smart materials and systems that control plant and biological functions. Smart packaging is a type of packaging, which in addition to performing the four basic functions of packaging such as protection, communication, convenience and containment, also offers several additional functionalities depending on the type of product. Changes in consumer preference for safe food have led to innovation in packaging technology. The market for smart packaging systems has a promising future by integrating them into packaging materials. For food retailers, smart packaging is a huge development in helping to reduce food waste. The aim of this study was to assess the awareness and attitudes of food manufacturers and retailers to the introduction of smart packaging systems into the Latvian market. A survey reflected knowledge about active and intelligent packaging and its possible introduction into the Latvian market. Ten manufacturers and ten food retailers from different regions in Latvia answered 16 questions, including how well they were informed about smart packaging and how much consumers would be willing to pay for it. In addition, the food manufacturer and food retailer confidence in the impact of smart packaging on a product storage quality was analyzed. The results revealed that manufacturers and retailers in Latvia have a poor understanding of the new opportunities which could be offered by using technologies of smart packaging. Key words: smart packaging, manufacturers, food retail, shelf life.
\end{abstract}

\section{Introduction}

Packaging is a crucial part of any advanced integrated product supply system. The main advantage is not just to preserve product's integrity and features starting with the production line and ending with the consumer impact on health and safety, but also to accelerate production and distribution and improve storage options (Robertson, 2006). Recently, huge strides have been made in the packaging technology development and application of new products and processes. Packaging is an essential bit of food processing and preservation, and it vastly influences the product's shelf-life. The material of the package can modify the product by physical and chemical alterations because of the particle migration into the nourishment. In case of food, it is vital to control the quality and safety of it during shipment and storage and extend the shelf-life of the goods (Dobrucka \& Cierpiszewski, 2014). The container accounts for the protection of the food from the medium, shielding it from physical, chemical and microbiological factors such as moisture, light, oxygen or microbial contamination that could influence the nature of the goods (Moldovan \& Pantea, 2015).

Some additional functionality could be to retain the integrity of a product and inhibit food decomposition, improve product properties such as appearance, flavour, smell, etc., respond actively to variations in product and package conditions, deliver product information, product history or state to the user, indicate seal integrity, or confirm product authenticity (Yam, Takhistov, \& Miltz, 2005).

'Smartness' of the packaging is a general term that incorporates a number of functionalities, depending on the product being bundled, including food, beverage, pharmaceutical, household products etc. Representatives of modern and expected functional 'smartness' would be in packages that:

- Maintain wholeness and actively stop food decomposition (shelf-life),

- Improve product characteristics (e.g. appearance, flavour, fragrance etc.),

- Respond actively to variations in product or package circumstances,

- Deliver product information, product history or state to the user,

- Help with the preparation and designate seal integrity,

- Verify the product's authenticity and prevent theft (Siegrist, 2008).

Smart packaging can already be found on the shelves, and many other active and intelligent packaging ideas are under development (Kuswandi et al., 2011). The central cause of tremendous progress that can be seen in the field of food packaging is the rise of nanotechnologies, which shapes nanometerscale materials of industrial and experimental significance. By introducing nanotechnologies, scientists have addressed the food nature, security and stability concerns (Sharma et al., 2017). The use of anti-microbial technologies and oxygen scavenging active food packaging systems, for example, sorbatereleasing low-density polyethylene (LDPE) film for cheese, has the capability to prolong the shelf-life of perishable foods while simultaneously improving its quality by decreasing the necessity of preservatives $\left(\mathrm{O}^{\prime}\right.$ Callaghan \& Kerry, 2016). In intelligent packaging, the container function turns on and off in response to 
shifting outer/inner states and can involve a message to the customer or end user as to the condition of the product (Ghaani et al., 2016).

The tendency in food packaging methods is the outcome of consumer preferences towards mildly processed foods with an improved shelf-life and convenience (Dobrucka \& Cierpiszewski, 2014). Furthermore, the recent trend of retail systems and evolving lifestyle are the incentives for the progression of original and innovative packaging techniques without compromising the safety and quality characteristics of the goods (Dainelli et al., 2008). A major boost for fresh food packaging methods is the advancing issues of foodborne microbial flashes which oblige the practice of packaging with antimicrobial effect along with the retention of food quality (Appendinia \& Hotchtkiss, 2002). Alterations in packaging started in the shape of metallic containers, adjustable packaging, electrically operated packaging machinery, aluminum foil, aseptic packaging and flexographic printing (Brody, Strupinsky, \& Kline, 2008). The emerging novelties in the packaging business will strengthen the economy by enhancing food protection, quality and by decreasing product losses (Mehmet, 2015).

One of the most debated topics is the ability to track packed products. New methods have been developed to assure the traceability during the entire journey of the goods from manufacturers to market suppliers (Ghaani et al., 2016). New electronic devices have been developed so that they can be attached to the package showing different properties, such as, heat, time of storage, a span of delivery, etc. These tracking systems certainly do not come for free, but the lack of them is an immense mistake for the producers. The main data that must be provided is the batch number of the fresh materials, the manufacturer ID and the biodegradability of the materials. In tracking systems, a significant part is performed by the labels that can include indicators that provide information for the customers, for example, branding and identification of the product (Moldovan \& Pantea, 2015). The aim of this study was to assess the awareness and attitudes of food manufacturers and retailers to the introduction of smart packaging systems into the Latvian market.

\section{Materials and Methods}

The analysis is based on a survey with two types of respondents: food retailers and food manufacturers. To participate in the survey, the top 10 Latvian food retailers were selected, based on their revenue in 2017 (data obtained from LFFC (Latvian Federation of Food Companies)). The chosen companies cover all the major Latvian regions: Riga (5 companies), Zemgale (1), Vidzeme (2), Latgale (1), Kurzeme (1). The second survey with similar questions was carried out with 10 different food manufacturers in Riga (6 companies), Zemgale (1), Vidzeme (1), Kurzeme (1), whose goods are distributed to the retail chains of Latvia (product group - packaged food products). The manufacturers were selected from those who provide perishable products (e.g dairy, fruits) and have their products on the shelves of all top 10 retailers. The methodology of the questionnaire was used to accomplish the research objective. For each of the 16 carefully chosen questions, the answers were either multiple-choice or interviewee produced response. The survey was issued to respondents using an online survey website VisiDati.lv. The number of respondents by sex were: 14 female and 6 male respondents. Most respondents (16) were between the ages of 35 and 50, 3 were between the ages of 25 and 35 , and 1 was over 50 years old. In response to their educational status, the preponderance of those who participated in the survey indicated that they had a master's or a bachelor's degree -18 ; 2 respondents held a professional degree. The qualitative method was used in the survey. During the questionnaire, the participants were encouraged to respond to the questions fully. If they needed clarification, some additional information was given to ensure that the respondent fully comprehends the question.

\section{Results and Discussion}

The survey provided an opportunity to analyse respondents' answers in order to clarify the manufacturer and retailer attitudes and knowledge regarding smart packaging. Smart packaging adds extra value to the consumer, shipping facilities, and companies that produce the above-mentioned products. For example, smart packaging can include tabs that indicate the freshness of an item, extend the shelf-life of a product, track shipping progress, and improve the protection of the products it is carrying. Smart packaging can help with a better supply management of retail, compliance complications, inventory management, and increase the protection of products during shipment (Marsh \& Bugusu, 2007). Smart packaging is not something new for Latvian manufacturers and retailers. However, the term 'smart packaging' was familiar to 8 retailers, but 2 manufacturers had never heard of it before.

Retailers always try to ensure surveillance of their goods, as the monitoring can reduce the amount or eliminate product discrepancies and faked products. Retailers can accomplish these tasks, they can reduce or minimize the write-off of discarded or crashed products if they use smart packaging (Phalgun, Nagendra, \& Shivakumarb, 2016). If a retailer chooses to forget such smart packaging solutions, they lose an option to regulate, and to control and minimize the write-off of spoiled items. 7 retailers consider smart 


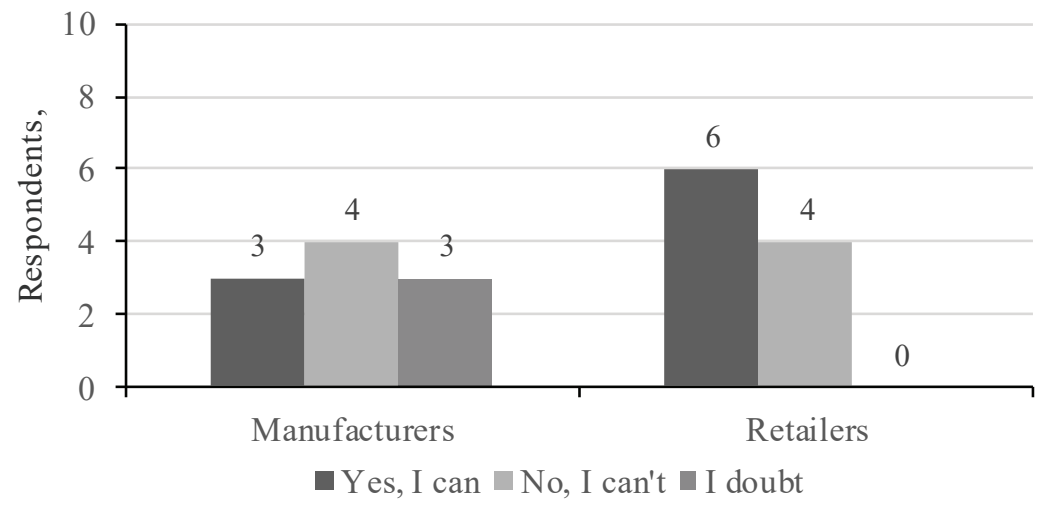

Figure 1. Respondents' ability to differentiate between active and intelligent packaging.

packaging as one of the correct decisions while 3 retailers answered with 'definitely no'. The response of this group reflects the answer to the question about the understanding of the term 'smart packaging'. 6 manufacturers, as one of the many criteria for evaluating the packaging, answered - 'yes, certainly', 4 gave a negative answer, 2 of the manufacturers chose 'definitely no' and 2 - 'do not care at all' answers. The difference of opinions of manufacturer respondents can be described as an inability to control the storage of packaged products delivered to the retailer. The retailer cannot ensure control of each item displayed on the shelf in the store.

Smart packaging is a relatively recent invention which has a lot of room for improvement. Modern technologies, which help in communication with consumers, such as printed electronics and the internet, are being exploited more and, therefore, rapid development of intelligent packaging can be observed (Seckin \& Yener, 2015). However, there are inevitable obstacles for such accelerated development. For example, some smart packaging is not costeffective to produce. Another obstacle is the way smart packaging affects legislation. Sustainability is an extra barrier since some of these technologies are challenging to recycle. And finally - timing, there are not many examples of proven success of it. Nonetheless, there exists stable and reproducible proof that smart packaging is a commercial success (Muizniece-Brasava \& Kirse, 2018). Figure 1 shows that 6 retailers can distinguish between active and intelligent packaging. An inverse measure of results was obtained from manufacturers. It is important to note that 7 manufacturers cannot distinguish term differences, out of which 3 doubt the ability to distinguish types of smart packages.

Only 1 out of both groups' respondents use smart packaging in their own production facilities (Figure 2) and this is a very low level currently for smart packaging products. The smart packaging industry is heavily divided, as both large and small-to-mediumsized enterprises continue to focus on narrow, one-off solutions, which prevents the planned implementation of smart packaging. The wide array of participants from infrastructure providers to packages, from brands to retailers themselves have prevented smart packaging introduction into the market.

5 manufacturers and 4 retailers answered that they try to introduce smart packaging in the production process. On the other hand, almost half respondents: 4 manufacturers and 5 retailers answered that they do not plan to integrate smart packaging into their own production process. Firstly, the reason could be the non-cost-effectiveness of the final product, because the shelf price level is one of the indicators of a product's demand. With the introduction of nanomaterials, the

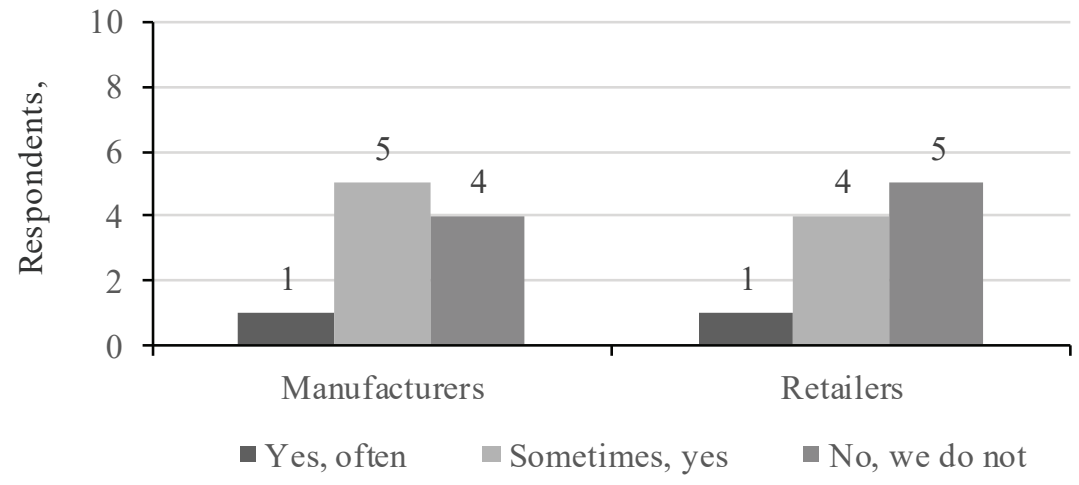

Figure 2. The use of smart packaging in production by respondents. 


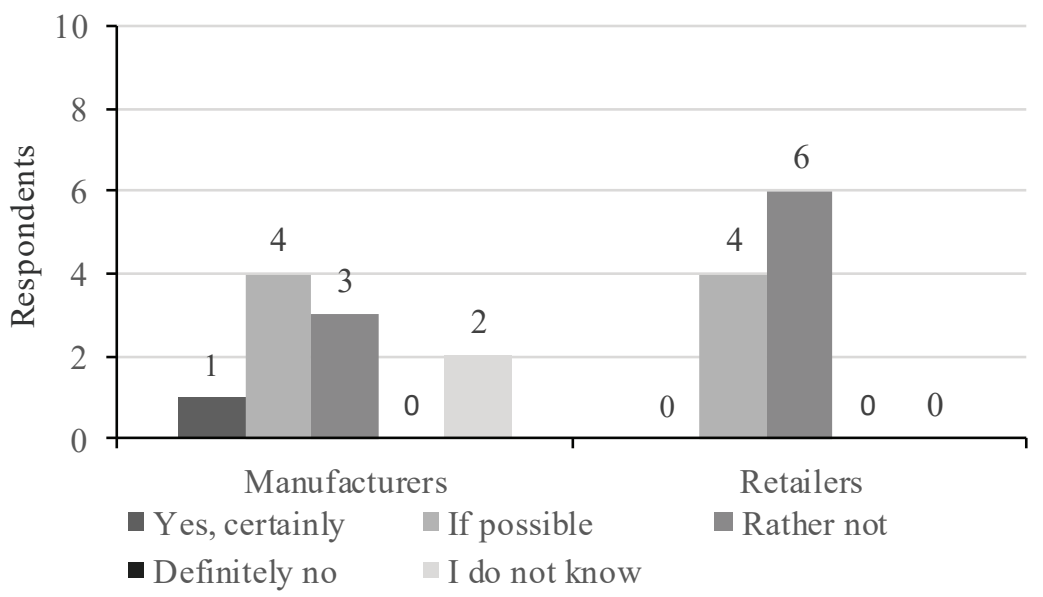

Figure 3. Respondents' readiness to pay more for smart packaging.

food industry will transform as never before. The $21^{\text {st }}$ century customers have witnessed an accelerated improvement in approval of nanomaterial-based food packaging due to the implementation of smart packaging. Smart materials will advance the existing storage systems while smart packaging will extend shelf life (Phalgun, Nagendra, \& Shivakumarb, 2016). Smart packaging provides consumers with extra information, communicates with retailers and manufacturers.

In Figure 3, you can see the respondents' opinions about readiness to pay a little more for smart packaging.

Most of the respondents among manufacturers and retailers are not ready to pay more for smart packaging. From the manufacturers' side, a stable position is not indicated; this may depend on the level of change in the cost price of the finished product. Retailers have a more comprehensive position. It depends on the implementation system in the production and sales process of the product in smart packaging (Carbone et al., 2016). Not all respondents are ready to pay more for smart packaging. Manufacturers must convey to the buyer that the smart packaging will be superior compared to equivalent competitors' products.
In Figure 4, manufacturers' opinion is divided into two parts where one half does not want to pay more for smart packaging and the other half of manufacturers are ready to pay up to $10 \%$ more.

Retailers have another position and they are ready to pay more for smart packaging. 3 retailers are ready to pay up to $5 \%$ more and 4 are ready to pay up to $10 \%$ more. Such difference in the answers reflects the difference in the conditions of the possibility of conveying smart packaging to the end customer. The first criterion among manufacturers is the choice over which channel the product will be sold - directly to the final customers or to the distribution channel where price increase will be perceived very negatively. There are multiple advantages for the retailer who can offer smart packaging on its shelves for the end customers. Smart packaging can help with a better supply chain management, compliance complications, managing inventory, and increase the security of products in the shipment process. Additionally, perishable items and fresh products can be continuously monitored for freshness and potential condition issues. In today's world, we are continuing to see increasing numbers of faked products, ranging from wine to high-end clothing, to big-name sports apparel. With smart

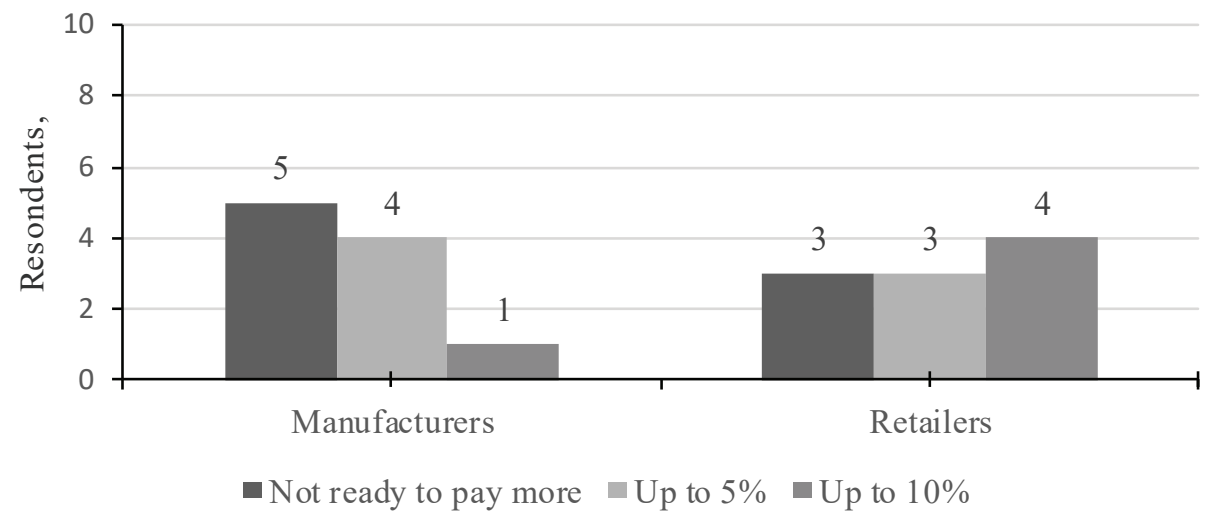

Figure 4. Number of respondents willing to pay more for smart packaging. 
packaging, retailers can constantly keep close tabs on inventory, shipments, and where things come from and go to (Seckin \& Yener, 2015).

When asked whether respondents believed that smart packaging would give food products an advantage over equivalent competitors' products without smart packaging, 6 manufacturers answered - yes, certainly. However, the opinion of retailers is divided: 5 of them were sure that smart packaging would give a superiority while the other 5 gave the answer - rather not. Questionnaire respondents were asked to analyse smart packaging also from the marketing position. 8 manufacturers believe that smart packaging can give the advantage for marketing and only 2 are unsure of it. The main retailers in the Latvian market do not have a single vision, 5 are sure that smart packaging is one of the marketing tools and 5 believe that this is a modern trend and, therefore, an integral part of the development of packaged products.

For food retailers, smart packaging is a huge development in helping to lessen food waste. We all know that most of our food products come stamped with a 'sell-by' date or 'best before' seal. Are these helpful guides? Perhaps, but they are nowhere near foolproof and are riddled with uncertainties and potential errors. This leads to massive amounts of food waste for both retailers and consumers, which in return can hurt the environment. Intelligent packaging can help reduce these common issues and deter large amounts of wasted food throughout the world ( $\mathrm{O}^{\text {' }}$ Callaghan \& Kerry, 2016).

Smart packaging also offers opportunities in the area of theft protection. Products with RFID (radio frequency identification) transponders integrated into the packaging can always be tracked. This not only helps to prevent theft from stores, but it also supports manufacturers with supply chain management, transport, and logistics. Products can be traced along the entire value chain, at the factory, in the warehouse (inventory management, goods in and out, etc.), and during transit to stores and end-users (location of goods) (Dobrucka \& Cierpiszewski, 2014).

Due to the demand for quickly prepared and ready-to-eat 'fresh' food products, with the delivery from centralized processing, as well as globalization of food business, major challenges for food safety and quality have arisen. Contemporary foodborne microbial upsurges are encouraging a search for innovative ways to restrain microbial growth in the foods whilst sustaining quality, safety and freshness (Biji et al., 2015). The first option is to utilize packaging to provide an enlarged margin of safety and quality. The following generation of food packaging may add materials with antimicrobial qualities. These packaging technologies could become the reason for the shelf-life extension of foods and could lessen the danger of pathogens. Antimicrobial polymers may gain use in other food-related industries (Majid et al., 2016). A very important point can be made around the purpose that both respondent groups expect from smart packaging in the production process and on the shelf itself. Manufacturer respondents answered: 2 were for protecting food against deterioration, 2 were for ensuring easy and convenient use, none were for the informing the consumer about the content of the food and 6 were for all the previously mentioned purposes. Most of the respondents want to receive as much information about product conditions as possible. Retailer respondents noted only two important criteria: 6 were for protecting food against deterioration and 4 were for informing the consumer about the content of the food.

Interesting differences can be deducted by analysing questions on the priority when choosing

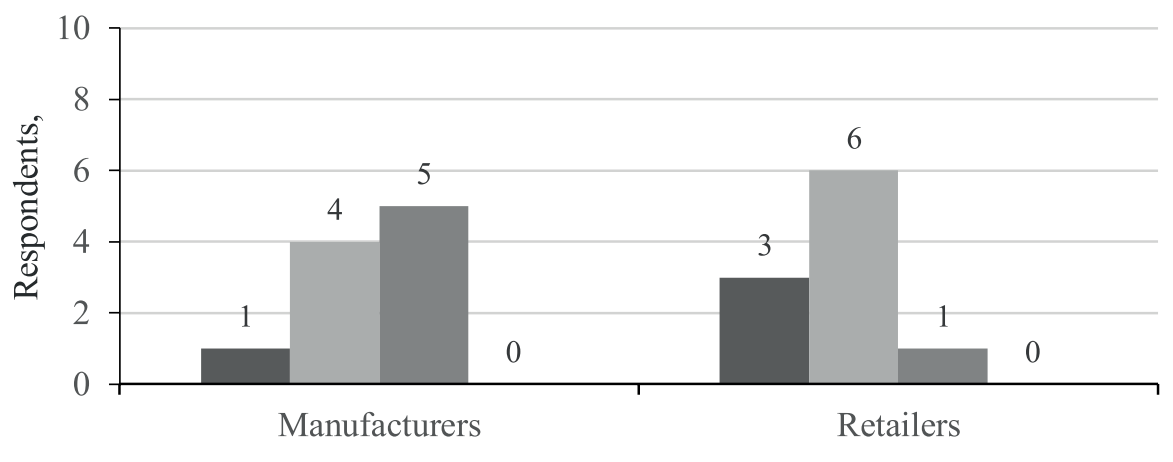

- Extending shelf life of food

Possibility to visually observe the history, freshness and quality of the food contained in the package

- Both of the aforesaid

Figure 5. Respondents' expectations from smart packaging. 
a package for products. 5 manufacturers consider that the most important criterion in smart packaging is environmental requirements (nature-friendly, recycling options), however, only 1 retailer voted for this criterion. The answer about requirements for packaging safety in direct contact with food was supported by 3 manufacturers and 5 retailers. The second important criterion for retailer respondents was product and packaging compatibility for longer sales times (quality, etc.), voted by 4 of them, and only by 2 manufacturers. Criteria of significance on the expectation from smart packaging are shown in Figure 5.

An insignificant part of manufacturers, 1, answered per criterion extending shelf life and 3 retailers answered the same. 4 manufacturers and 6 retailers voted for the possibility to visually observe the history, freshness and quality of the food contained in the package. 5 manufacturers voted for both criteria and only 1 retailer voted for both criteria. Survey reflects the direction of each group where we can trace the desire of manufacturers when using smart packaging technologies to receive maximum of what can be offered by this technology. But retailers want to solve clearly defined tasks.

An important section in this survey after all questioning was to provide an answer on the following topic: what should be done to promote the positive attitude of society towards smart packaging. 5 manufacturers versus 4 retailers answered that customers should be educated through advertising. A similar ratio in the responses (5 versus 4 ) was given to the idea to offer product within price promotion and only 2 retailer respondents considered that the sales or promotion should be done only with trusted product brands.

The state of food items frequently relies upon their perishability. Perishable foods need a cool environment to preserve quality and freshness throughout transit and storage. By controlling the extent to which perishable foods face degradation promoting factors (like oxygen, light) both manufacturers and retailers are able to manage their perishability. The shape and the material of the food container play a crucial and decisive role in food quality and shelf-life. Packaging chiefly affects the barrier features to create an irrefutable food environment (Singh, Wani, \& Langowski, 2017).

\section{Conclusions}

1. According to the survey results, top 10 food retailers and food manufacturers in Latvia have little understanding of the new opportunities which could be unveiled by using technologies of smart packaging. The numerous listed benefits and respondent expectations from smart packaging result in the belief that both groups are open to new trends, ready to try them, study them and are prepared to pay for smart packaging.

2. The upside potential is large, as smart packaging is posed to solve numerous weighty business issues from stock-outs to counterfeiting to product spoilage to customer satisfaction, communication and retention.

3. Smart packaging is organizing around a set of few applications, which are driving supply chain efficiency, followed closely by product integrity and customer engagement.

4. The results proved that the crucial factors for the manufacturers and retailers are the quality, the efficient use, and the ability to control storage time, which, in turn, are what the smart packaging offers.

5. Packaging manufacturers have an opportunity to move away from purely price-based competition, increase customer loyalty, and offer their customers real, long-term added value. To achieve this, it is fundamental for packaging manufacturers to design and develop new products and services and work with their customers to bring them to market.

\section{References}

1. Biji, K.B., Ravishankar, C.N., Mohan, C.O., \& Srinivasa Gopal, T.K. (2015). Smart packaging systems for food applications: a review. Journal of Food Science and Technology. 52(10), 6125-6135. DOI: 10.1007/ s13197-015-1766-7.

2. Brody, L.A., Strupinsky, E.R., \& Kline, L.R. (2001). Active Packaging for Food Applications. Boca Raton: CRC Press, Taylor \& Francis Group.

3. Carbone, M., Tommasa Donia, D., Sabbatella, G., \& Antochia, R. (2016). Silver nanoparticles in polymeric matrices for fresh food prackaging. Journal of King Saud University-Science. 28, 273-279. DOI: 10.1016/j. tifs.2008.09.011.

4. Dainelli, D., Gontard, N., Spyropoulos, D., Zondervan-van den Beuken, E., \& Tobback, P. (2008). Active and intelligent food packaging: legal aspects and safety concerns. Trends, Food Science Technology. 19 (1), 103-112. DOI: 10.1016/j.tifs.2008.09.011.

5. Dobrucka, R., \& Cierpiszewski, R. (2014). Active and intelligent packaging food - research and development - a review. Polish Journal of Food and Nutrition Scinece. 64 (1), 7-15. DOI: 10.2478/ v10222-012-0091-3. 
6. Ghaani, M., Cozzolino, C.A., Castelli, G., \& Farris, S. (2016). An overview of the intelligent packaging technologies in the food sector. Trends in Food Science \& Technology. 51, 1-11. DOI: 10.1016/j. tifs.2016.02.008.

7. Kuswandi, B., Jayus, Y.W., Abdullah, A., Heng, L.Y., \& Ahmad, M. (2011). Smart packaging: sensors for monitoring of food quality and safety. Sensing and Instrumentation for Food Quality and Safety. 5, $137-$ 146. DOI: $10.1007 / \mathrm{s} 11694-011-9120-\mathrm{x}$.

8. Marsh, K., \& Bugusu, B. (2007). Food packaging: Roles, Materials, and Environmental issues. Journal of Food Science. 72(3), 39-55. DOI: 10.1111/j.1750-3841.2007.00301.x.

9. Majid, I., Nayik, G.A., Dar, S.M., \& Nanda, V. (2016). Novel food packaging technologies: Innovations and future prospective. Journal of the Saudi Society of Agricultural Sciences. 17, 454-462. DOI: 10.1016/j. jssas.2016.11.003.

10. Mehmet, S.A. (2015). Assessing consumers' adoption of active and intelligent packaging. British Food Journal. 117(1), 157-177. DOI: 10.1108/BFJ-07-2013-0191.

11. Moldovan, L., \& Pantea, G. (2015). Development of innovative biodegradable packaging system to improve shelf life, Quality and Safety of fresh products. Journal of EcoAgriTourism, Calita Terra. 11 (1), 31-34.

12. Muizniece-Brasava, S., \& Kirse, A. (2018). Attitudes of Latvian consumers to traditional and ecofriendly food packaging materials: comparison of 2007 and 2017. In: International scientific conference "Engineering for rural development": proceedings. Conference Paper. 23.-25.05.2018. (pp. 1948-1954). Jelgava, Latvia. DOI: 10.22616/ERDev2018. 17. N 560.

13. O'Callaghan, K.A.M., \& Kerry, J.P. (2016). Consumer attitudes towards the application of smart packaging technologies to cheese products. Food Packaging and Shelf Life. 9, 1-9. DOI: 10.1016/j.fps1.2016.05.001.

14. Phalgun, M., Nagendra, C., \& Shivakumarb, N. (2016). Smart packaging of food for the 21 st century - A review with futuristic trends, their feasibility and economics. Journal of ScienceDirect. 5(10), 2101821022. DOI: 10.1016/j.matpr.2018.06.494.

15. Robertson, G. (2006). Food Packaging Principles and Practices, Taylor \& Francis, Boca Raton. pp. 733.

16. Seckin, A.M., \& Yener, U. (2015). Assessing consumers' adoption of active and intelligent packaging. British Food Journal. 117 (1), 157-177. DOI: 10.1108/BFJ-07-2013-0191.

17. Sharma, C., Dhiman, R., Rokana, N., \& Panwar, H. (2017). Nanotechnology: An Untapped Resource for Food Packaginmg. Frontiers in Microbiology. 8, 1-22. DOI: 10.3389/fmicb.2017.01735.

18. Siegrist, M. (2008). Factors influencing public acceptance of innovative food technologies and products. Trends in Food Science \& Technology. 19, 603-608. DOI: 10.1016/j.tifs.2008.01.017.

19. Singh, P., Wani, A.A., \& Langowski, H-C. (2017). Food packaging materials. Boca Raton: CRC Press, Taylor \& Francis Group.

20. Yam, K.L., Takhistov, P.T., \& Miltz, J. (2005). Intelligent packaging: concepts and applications. Journal of Food Science. 70(1), 1-10. DOI: 10.1111/j.1365-2621.2005.tb09052.x. 